\title{
Desenvolvimento de bezerros de corte desmamados aos 80 ou 152 dias até os 15-16 meses de idade
}

\author{
Ricardo Zambarda Vaz ${ }^{1}$, José Fernando Piva Lobatoํㅜ, Leonir Luiz Pascoal ${ }^{2}$
}

1 Departamento de Zootecnia - Faculdade de Agromonia - UFRGS.
2 Departamento de Zootecnia - Centro de Ciências Rurais - UFSM.

RESUMO - Avaliou-se o desenvolvimento de bezerros de corte submetidos a duas idades de desmame: precoce, em média com 80 dias de idade; convencional, em média com 152 dias de idade. Foram utilizados 105 bezerros Braford, nascidos nos anos de 2004 e 2005. Após o desmame, os bezerros foram mantidos em pastagens cultivadas de milheto (Pennisetum americanum) no primeiro e segundo verão e, no inverno/primavera, de aveia e azevém (Avena strigosa Schreb + Lolium multiflorum Lam). Foram avaliados os pesos corporais, ganhos de pesos médios diários e condição corporal. Houve interação significativa entre idade de desmame e ano para o ganho médio diário, tanto no desmame precoce como no desmame convencional, na pastagem de aveia e na de azevém. No período entre as duas idades de desmame, o ganho médio diário no desmame precoce foi maior em 2004 que em 2005 (0,499 vs 0,468 kg, respectivamente) e no desmame precoce ocorreu maior ganho médio diário em 2005 (0,493 vs $0,631 \mathrm{~kg}$, respectivamente). Na pastagem de aveia e azevém, o ganho médio diário dos animais do desmame precoce em 2004 $(0,666 \mathrm{~kg})$ foi menor que em $2005(0,760 \mathrm{~kg})$, no entanto, não houve diferença entre os anos no caso dos animais do desmame convencional $(0,720$ e $0,723 \mathrm{~kg}$, respectivamente). Durante os segundos verões, não houve diferença no ganho médio diário dos animais entre os desmames precoce e convencional. O peso dos animais do desmame precoce $(158,2 \mathrm{~kg})$ foi superior ao daqueles do desmame convencional $(147,7 \mathrm{~kg})$ no início da pastagem de inverno, porém, não diferiu no final. Ao final do verão, quando os novilhos atingiram 15-16 meses de idade, o peso corporal foi similar entre os desmames precoce (340,1 kg e 4,14 pontos) e convencional (332,8 kg e 4,15 pontos). A condição corporal final em 2004 foi maior (4,34) que em 2005 (3,96 pontos). Bezerros desmamados aos 80 dias de idade e alimentados adequadamente têm desempenho semelhante aos desmamados aos 152 dias de idade, atingindo desenvolvimento e acabamento adequados de abate para mercados específicos aos 15-16 meses de idade.

Palavras-chave: Braford, condição corporal, desmame precoce, ganho de peso, novilhos

\section{Performance until the age of $15-16$ months of beef calves weaned at 80 or 152 days of age}

\begin{abstract}
The performance of beef calves submitted to two weaning ages (early weaning, at an average age of 80 days; conventional weaning, at an average age of 152 days) was evaluated. One hundred and five Braford calves born in 2004 and 2005, after weaning, were kept on pastures cultivated with pearl millet (Pennisetum americanum) in the first and second summer and, in winter/spring, they were kept on pastures with oat and ryegrass (Avena strigosa Schreb + Lolium multiflorum Lam). Body weight (BW), average daily weight gain (ADWG) and body condition (BC) were evaluated. There was a significant interaction among age at weaning and year for daily weight gain for early weaning as well as for conventional weaning on oat and ryegrass pastures. In the period between the two weaning ages, the daily weight gain in early weaning was higher in 2004 than in 2005 ( 0.499 vs $0.468 \mathrm{~kg}$, respectively) and for early weaning, higher daily weight gain occurred in 2005 ( 0.493 vs. $0.631 \mathrm{~kg}$, respectively). On oat and ryegrass pasture, average daily weight gain for early weaned animals in 2004 $(0.666 \mathrm{~kg})$ was lower than in $2005(0.760 \mathrm{~kg})$, however, there was no difference among years for conventional weaned animals ( 0.720 and $0.723 \mathrm{~kg}$, respectively). During second summer periods, average daily weight gain did not differ among early and conventional weaned animals. Weight of early weaned animals $(158.2 \mathrm{~kg})$ was higher than conventional weaned animals (147.7 kg) in the beginning of winter grazing; however, it did not differ at the end. In the end of the summer, when calves were 15-16 months of age, body weight was similar among early weaned (340.1 and 4.14 points) and conventional (332.8 $\mathrm{kg}$ and 4.15 points) weaned animals. Final body condition, in 2004, was higher (4.34) than in 2005 (3.96 points). Calves weaned at 80 days of age and adequately fed present similar development as those weaned at 152 days of age, achieving development and finishing conditions to be slaughtered for specific markets at 15-16 months of age.
\end{abstract}

Key Words: body condition, Braford, early weaning, steers, weight gain 


\section{Introdução}

A competitividade da pecuária de corte depende da máxima eficiência produtiva e do aumento da rentabilidade do sistema (Pötter et al., 1998). A redução da idade ao abate é um dos principais fatores responsáveis pela eficiência produtiva e pelo aumento dos índices de produtividade dos rebanhos (Beretta et al., 2002b).

$\mathrm{O}$ abate de novilhos em idade inferior aos 24 meses permite aumentar o número de vacas nos rebanhos de cria pela eliminação de categorias de recria, o que melhora a taxa de desfrute (Pötter et al., 1998), por meio do aproveitando da eficiência animal e do potencial de crescimento para conversão do alimento consumido em produção (Restle et al., 1999b; Beretta et al., 2002a). Beretta et al. (2002b), observaram menores produções de peso corporal/ha e taxas de desfrute em sistemas produtivos com idade ao abate superior a 24 meses de idade.

Em sistemas de ciclo completo, a eficiência reprodutiva dos rebanhos de cria é importante (Beretta et al., 2002b). Assim, práticas de manejo que influenciem o desempenho reprodutivo afetam os indicadores de desempenho do rebanho (Rosado Júnior \& Lobato, 2009). Técnicas como o desmame precoce têm sido analisadas com o intuito de aumentar a taxa de prenhez e a produtividade de vacas de corte (Restle et al., 2001; Almeida \& Lobato, 2002; Vaz \& Lobato, 2010). Entretanto, todos os benefícios em ganho de peso e acúmulo de condição corporal das vacas (Lobato et al., 2000; Restle et al., 2001; Vaz \& Lobato, 2010), determinantes de melhores índices reprodutivos, não podem ser perdidos por má alimentação dos bezerros no pós-desmame. O desmame precoce, se conduzido de maneira correta, não prejudica o peso ao abate de machos aos 24 meses de idade (Albospino \& Lobato, 1994; Restle et al., 1999a; Almeida et al., 2003).

Existem poucas informações sobre a produção de animais para abate aos 15-16 meses de idade desmamados a idades inferiores aos 100 dias. A literatura é contraditória sobre o desenvolvimento até um ano de idade. Alguns autores têm relatado diferenças no peso corporal dos animais com 13 a 16 meses de idade (Simeone \& Lobato, 1998; Lobato et al., 2007) em situação de alimentação limitante, enquanto outros relatam desenvolvimento similar entre animais desmamados precocemente ou na idade convencional (Albospino \& Lobato, 1994; Restle et al., 1999ab; Almeida et al., 2003; Pötter et al., 2004).

O objetivo neste estudo foi avaliar os efeitos de duas idades de desmame no desenvolvimento de bezerros até os 15-16 meses de idade em uma típica propriedade comercial, de ciclo completo.

\section{Material e Métodos}

O experimento foi realizado na Granja Itú, município de Itaqui, fronteira oeste do Rio Grande do Sul, com latitude $29^{\circ} 12^{\prime}$ sul e longitude $55^{\circ} 36^{\prime}$ oeste, no período entre setembro de 2004 a janeiro de 2007 . O relevo da região é ondulado, com coxilhas de solos profundos, naturalmente ácidos, com textura superficial média. O solo é classificado como latossolo vermelho distrófico (EMBRAPA, 1999) e o clima é subtropical, conforme classificação de Köppen (Moreno 1961).

Foram utilizados 105 bezerros Braford, distribuídos de acordo com o manejo utilizado com as suas mães nas seguintes idades de desmame: desmame precoce: bezerros desmamados com média de 80 dias de idade; desmame convencional: bezerros desmamados com média de 152 dias de idade.

O rebanho de vacas mães dos bezerros foi avaliado por dois anos consecutivos. Dessa forma, a distribuição dos animais não foi uniforme nos anos, pois foram mantidas no rebanho somente as vacas que repetiram prenhez e que foram submetidas à mesma idade de desmame nos dois anos seguidos, ou seja, houve animais contemporâneos nas duas idades de desmame, nos dois anos.

As idades ao desmame tiveram diferentes números de repetições: 71 e 34 bezerros para desmame precoce e desmame à idade convencional, respectivamente, nascidos na primavera de 2004 ( 7 de setembro a 15 de outubro - 56 bezerros) e de 2005 ( 5 de outubro a 1 de dezembro - 49 bezerros), filhos de primíparas no primeiro ano e de secundíparas no segundo ano.

Os bezerros, até as idades ao desmame, foram mantidos em pastagem nativa com carga animal de $320 \mathrm{~kg}$ de peso corporal/ha no primeiro ano. Durante o segundo período reprodutivo (10/12/2005 a 2/2/2006) das vacas, os bezerros do desmame convencional foram mantidos com suas mães em pastagem de capim-braquiária (Brachiaria brizantha cv Marandu).

Após os desmames, independentemente da época, os bezerros foram colocados em currais por dez dias e liberados para pastejos horários diariamente no quarto dia pósdesmame. Após esse período de 10 dias, os bezerros do desmame precoce foram mantidos durante o período de verão e outono em pastagem cultivada de milheto (Pennisetum americanum (L.) Leeke) cv. Comum, com lotação de 8 bezerros/ha, com exceção dos meses de abril, quando pastejaram braquiária brizanta (Brachiaria brizantha cv Marandu).

Os bezerros do desmame convencional, após os 10 dias em curral, foram juntados aos seus contemporâneos do 
desmame precoce na, pastagem de verão formando um grupo único. Todos os bezerros, no período pós-desmame até o início da pastagem de inverno, receberam suplementação balanceada na proporção de $1 \%$ do peso corporal, com $18 \%$ de proteína bruta e $75 \%$ de nutrientes digestíveis totais, formulada com farelo de soja, casca de soja, farelo de trigo, farelo de arroz integral, sal comum, calcário calcítico e mistura mineral. Durante o período de outono, inverno e primavera, ou seja, meses de maio até novembro, pastejaram aveia (Avena strigosa) e azevém (Lolium multiflorum Lam.) na lotação de 5 bezerros/ha. No período de pastagens de outono inverno/primavera de 2004, nos meses de junho a outubro, foi utilizada suplementação com casca de soja na quantidade de $0,5 \%$ do peso corporal.

No segundo verão, após o término de pastejo em aveia e azevém, os novilhos das duas idades de desmame nascidos em 2004 e 2005 foram mantidos em pastagem cultivada de milheto e em braquiária brizanta, respectivamente.

As estimativas da massa de forragem disponível foram realizadas pelo método comparativo (Haydock \& Shaw, 1975). As amostras foram analisadas quanto aos teores de proteína bruta $(\mathrm{PB})$ e fibra detergente neutro (FDN), estimados segundo técnicas descritas pela AOAC (1984).

Os bezerros foram pesados ao nascimento nos desmames precoce e convencional e, posteriormente, a cada 28 dias, até o final do período experimental. Os ganhos de pesos diários foram determinados pela diferença de peso entre as pesagens. Nas pesagens também foi realizada avaliação do escore de condição corporal (ECC; Lowman et al., 1973), com atribuição de valores de 1 a 5, em que 1 = muito magro e 5 = muito gordo.

Durante o período com suplementação, os bezerros receberam suplementação mineral via suplemento e, quando em pastagens cultivadas de inverno/primavera e de verão, tiveram livre acesso a cochos com sal comum e ortofosfato bicálcico com 80 ppm de fósforo. Vacinações contra febre aftosa e clostridioses foram feitas nas datas recomendadas.
O controle de endoparasitas foi realizado com dosificações estratégicas de vermífugos de amplo espectro e o de ectoparasitas (carrapatos, bernes e miíases), com produtos específicos para os controles.

O delineamento experimental foi o inteiramente casualizado em arranjo fatorial $2 \times 2$, com duas idades de desmame e dois anos de observação. Como o trabalho iniciou-se com vacas primíparas aos 3 anos de idade (2004) e como elas se tornaram secundíparas aos 4 anos (2005), e esses dois efeitos são totalmente confundidos, foram considerados efeito conjunto de ano de nascimento do bezerro e idade da vaca.

Os resultados foram submetidos à análise de variância e ao teste $\mathrm{F}$ utilizando-se o seguinte modelo matemático:

$$
\mathrm{Y}_{\mathrm{ijk}}=\mu+\mathrm{T}_{\mathrm{i}}+\mathrm{A}_{\mathrm{j}}+\left(\mathrm{T}^{*} \mathrm{~A}\right)_{\mathrm{ij}}+\mathrm{IN}_{\mathrm{k}}+\Sigma_{\mathrm{ijk}}
$$

em que: $Y_{i j k}=$ variáveis-dependentes; $\mu=$ média de todas as observações; $\mathrm{D}_{\mathrm{i}}=$ efeito do i-ésimo idade de desmame, em que $\mathrm{i}=1$ (desmame precoce) ou 2 (desmame convencional); $A_{j}=$ efeito do conjunto j-ésimo ano e idade da vaca; $I D * A_{i j}$ $=$ efeito da interação i-ésimo idade de desmame $\times$ efeito do $\mathrm{j}$-ésimo conjunto ano e idade da vaca; $\mathrm{IN}_{\mathrm{j}}=$ covariável idade do animal de ordem $\mathrm{j} ; \Sigma_{\mathrm{ijkl}}=$ erro residual.

As análises foram realizadas com auxílio do procedimento GLM e os dados analisados pelo programa estatístico SAS, versão 6.08 (SAS, 1997), adotando-se 5\% como nível de significância máxima.

\section{Resultados e Discussão}

Os valores qualitativos das pastagens (Tabela 1 ) foram próximos aos observados em outros trabalhos realizados no Rio Grande do Sul (Freitas et al., 1976; Pilau \& Lobato, 2006), com pequenas variações, devidas provavelmente à diversidade de clima e à fertilidade de solo de cada região.

Os pesos médios na ocasião dos desmames precoce e convencional foram de 89,1 e 121,2 kg e 84,7 e 121,7 kg para

Tabela 1 - Massa de forragem e percentuais de proteína bruta e fibra em detergente neutro das pastagens utilizadas

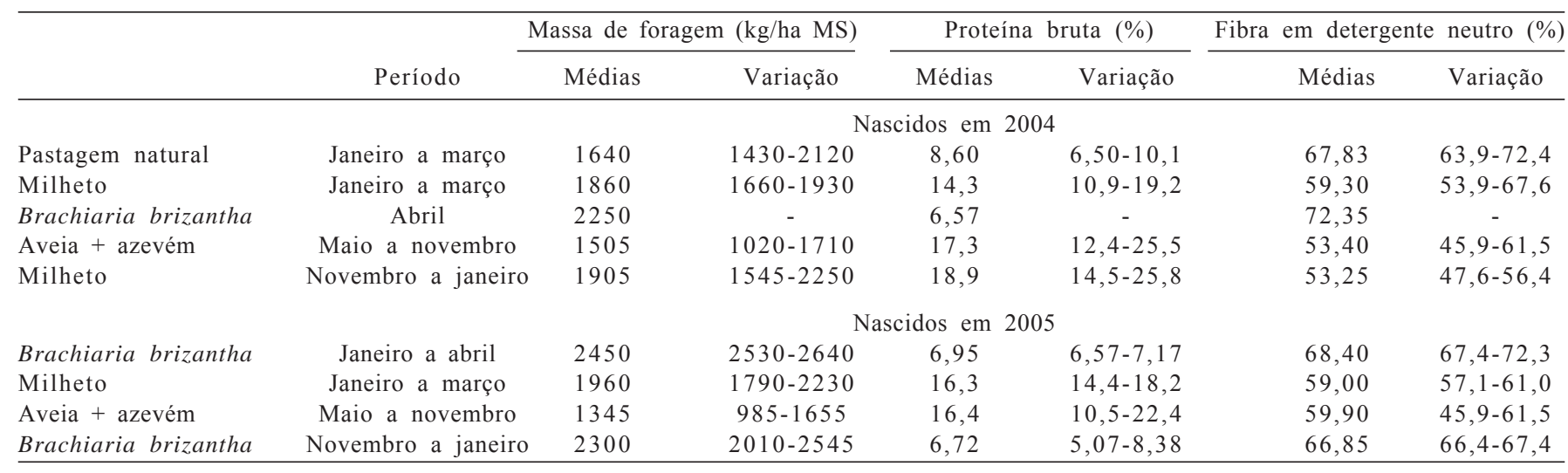


bezerros do desmame precoce e do desmame à idade convencional e para os anos 2004 e 2005, respectivamente, e não diferiram entre as idades de desmame nem entre os anos de avaliação (Tabela 2). Trabalhos de pesquisa mostram diferenças no peso à idade do desmame convencional entre bezerros desmamados precocemente e os desmamados na idade convencional aos 6 - 7 meses de idade (Restle et al., 1999a; Almeida et al., 2003; Lobato et al., 2007).

Lobato et al. (2007), em pesquisa com bezerros desmamados aos 180 dias em comparação àqueles desmamados aos 70 dias, mostraram superioridade de 13,1\% em peso corporal para animais desmamados à idade convencional. Restle et al. (1999a) notaram diferença de $13,9 \%$ no peso aos 7 meses de idade favorável aos bezerros do desmame convencional aos 210 dias em comparação aos desmamados aos 90 dias de idade.

O peso dos animais das duas idades de desmame foi similar na ocasião do desmame convencional. O ganho médio diário no período entre os dois desmames sofreu interação entre idade de desmame e ano de observação. Para os animais do desmame precoce, o ganho médio diário em 2004 foi maior que em 2005, enquanto, no desmame à idade convencional, o ganho de peso foi maior em 2005 e menor em 2004. O aumento no ganho médio diário dos bezerros do desmame à idade convencional no segundo ano deve estar associado à maior produção de leite das vacas secundíparas, pois a produção de leite aumenta até a idade adulta da vaca (Restle et al., 2001; Cerdótes et al., 2004b; Vieira et al., 2005). Outro aspecto importante são as espécies forrageiras usadas nos dois anos de aleitamento dos bezerros desmamados à idade convencional (Tabela 1), que influenciam não apenas a produção de leite das mães, mas também a disponibilidade e a qualidade do pasto para os bezerros. O efeito de ano inclui vários aspectos, como o clima, a idade da vaca e o tipo do pasto, mas não foi possível no experimento separar esses efeitos. Segundo dados pluviométricos e climáticos da região, houve desuniformidade entre os meses do ano e entre os mesmos meses entre os anos.
Ganhos de pesos diários superiores para bezerros desmamados a idades maiores no período entre as duas idades de desmame foram relatados por Restle et al. (1999a) e Lobato et al. (2007), de 54,67\% e 34,00\%, em trabalho com bezerros dos 90 aos 210 dias e dos 70 aos 180 dias, respectivamente.

A média de dois anos para o ganho de peso no período entre os dois desmames foi de 0,483 vs $0,562 \mathrm{~kg}$, respectivamente, para bezerros do desmame precoce e do desmame convencional. No ano de 2005, o ganho médio diário dos animais do desmame à idade convencional superou em $16,4 \%$ o daqueles desmamados precocemente, mas essa diferença na média é inferior aos $54,67 \%$ pró-desmame convencional encontrados por Restle et al. (1999a) em bezerros dos 3 aos 7 meses.

O menor ganho de peso em animais desmamados a idades precoces (Simeone \& Lobato, 1998; Restle etal., 1999a; Almeida et al., 2003; Lobato et al., 2007) no período pós-desmame devese ao estresse do desmame precoce. Restle et al. (1999a) afirmaram que a submissão de bezerros a uma alimentação quando seu trato digestório não está completamente desenvolvido determina menores ganhos de peso, pois o bezerro não obtém da pastagem quantidade de nutrientes suficientes para manter os ganhos de quando ao pé da vaca.

O maior ganho de peso dos bezerros no intervalo das duas idades de desmame foi mais marcante nos animais nascidos no segundo ano de observação (2005) e essa diferença no ganho médio diário dos animais nascidos em 2004 entre as duas idades de desmame, embora significativa, foi de baixa magnitude. Em parte, isso foi devido ao ano atípico, com períodos de estiagem prolongados e chuvas abaixo do normal no intervalo compreendido nas datas do desmame (70 e 14 mm durante os meses de janeiro e fevereiro, respectivamente), ocasionando decréscimo na quantidade e qualidade da pastagem nativa pastejada pelas vacas, fato agravado pela alta carga animal utilizada (320 kg/ha).

Esses fatores repercutiram de forma negativa na produção de leite e no peso à desmama dos bezerros. A

Tabela 2 - Pesos médios nas idades de desmame, ganhos médios diários entre idades de desmame e pós-desmame à idade convencional, de acordo com o ano

\begin{tabular}{|c|c|c|c|c|c|c|c|}
\hline & \multicolumn{3}{|c|}{ Desmame precoce } & \multicolumn{3}{|c|}{ Desmame convencional } & \multirow[t]{2}{*}{$\mathrm{CV}(\%)$} \\
\hline & 2004 & 2005 & Média & 2004 & 2005 & Média & \\
\hline Desmame precoce, $\mathrm{kg}$ & 88,1 & 90,1 & 89,1 & 86,7 & 82,7 & 84,7 & 14,0 \\
\hline Ganho médio diário, $\mathrm{kg}$ & $0,499 a$ & $0,468 \mathrm{~b}$ & 0,483 & $0,493 b$ & $0,631 \mathrm{a}$ & 0,562 & 32,4 \\
\hline Peso $01 / 05^{\#}$ & 168,0 & 148,5 & $158,2 \mathrm{~A}$ & 152,9 & 142,6 & $147,7 \mathrm{~B}$ & 13,3 \\
\hline Ganho médio diário pós-desmame convencional* & 0,831 & 0,492 & $0,662 \mathrm{~A}$ & 0,593 & 0,335 & $0,464 \mathrm{~B}$ & 25,1 \\
\hline
\end{tabular}

a,b médias na mesma linha, diferem $(\mathrm{P}<0,05)$ pelo teste $\mathrm{t}$.

A,B médias na mesma linha, diferem $(\mathrm{P}<0,05)$ pelo teste $\mathrm{F}$.

\# Peso ao início das pastagens de inverno.

* Ganho de peso após o desmame à idade convencional nos meses de março e abril. 
menor qualidade do campo nativo onde os bezerros nascidos em 2004 permaneceram junto com suas mães, 8,60 e $67,83 \%$ de proteína bruta e fibra detergente neutro, respectivamente (Tabela 1). Nessas condições vacas amamentando não apresentam bom desempenho reprodutivo, e a produção de leite é insuficiente para desenvolvimento adequado do bezerro (Quadros \& Lobato, 1997).

Em condições de elevada carga animal, ocorrem menores produções de leite e menor peso à desmama dos bezerros. Quadros \& Lobato (1997) trabalharam com duas cargas animais por hectare $(240$ e $320 \mathrm{~kg}$ ) e observaram que as vacas conduzidas com maior disponibilidade de pastagem produziram mais leite e proporcionaram maiores ganhos de peso aos bezerros. A produção de leite da vaca é importante fonte da variação no peso à desmama de bezerros e nos ganhos de peso do nascimento à desmama (Ribeiro \& Restle, 1991). Além disso, as vacas no ano de 2004 eram primíparas aos 3 anos. Menores produções de leite de vacas primíparas em comparação às multíparas foram observadas por Restle et al. (2001) e Cerdótes et al. (2004b), por estarem em crescimento e terem suas exigências aumentadas (Freetly, 1999), contribuindo para menor desempenho dos bezerros.

O consumo de alimentos é regulado por fatores referentes ao animal (peso corporal, nível de produção), ao alimento (fibra, valor energético) e às condições de alimentação (disponibilidade). Além disso, os fatores ambientais aos quais o animal está exposto também podem afetar o consumo (NRC, 1996).

Bezerros desmamados precocemente e postos em confinamento com dieta balanceada ( $50 \%$ de silagem de aveia-preta pré-seca e $50 \%$ de concentrado) alcançaram peso médio de $209 \mathrm{~kg}$ na data do desmame à idade convencional, peso superior ao daqueles desmamados à idade convencional, $192 \mathrm{~kg}$ em média (Restle et al., 2002a).

Nos meses de março e abril, após o desmame à idade convencional, os animais das duas idades de desmame permaneceram nas mesmas condições de alimentação, com ganho de peso médio diário superior $(\mathrm{P}<0,05)$ para os bezerros desmamados precocemente $(0,662 \mathrm{vs} 0,464 \mathrm{~kg})$. Os menores ganhos de peso dos animais do desmame à idade convencional podem ser, em parte atribuídos, ao estresse do desmame, o qual, independentemente da idade em que é realizado, causa transtornos no desenvolvimento animal. O melhor ganho de peso dos bezerros do desmame precoce resultou em peso mais elevado no início de maio (158,2 vs $147,7 \mathrm{~kg}$ ), quando os animais passaram à pastagem de inverno.

O ganho médio diário (Tabela 3 ) durante o período outono-inverno-primavera (março/novembro) foi maior nos bezerros desmamados precocemente $(0,689$ vs $0,652 \mathrm{~kg})$. Lobato et al. (2007), em pesquisa com novilhos desmamados aos 180 e 70 dias, não observaram diferença no ganho de peso durante o mesmo período, mas os animais do desmame precoce manifestaram maiores $(\mathrm{P}<0,05)$ ganhos de peso durante o segundo período de outono-inverno-primavera.

O maior ganho de peso dos animais do desmame precoce pode ser explicado também pelo ganho compensatório após o período de estresse pós-desmama, uma vez que foram desmamados antes. Não significa que, necessariamente, o ganho compensatório se manifeste somente por uma restrição alimentar, mas por variações na natureza e duração da restrição, determinando a severidade dessa restrição e interação entre esses fatores (Di Marco, 1998).

Poppi \& McLennan (1995) verificaram em animais alimentados adequadamente maior eficiência alimentar após um período de restrição, em decorrência do maior consumo de energia metabolizável, que foi superior às exigências de mantença. Bail et al. (2000) trabalharam com novilhos durante a recria em pastagem nativa ou em pastagem cultivada de verão no período anterior à terminação e determinaram pesos ao início de 270 e $340 \mathrm{~kg}$, respectivamente, ao início da terminação. Observaram que a maior restrição alimentar em pastagem nativa na fase de recria resultou em maiores consumos de matéria seca e de energia digestível durante a terminação de novilhos e concluíram que os novilhos apresentaram crescimento compensatório durante essa fase.

Tabela 3 - Desempenho de bezerros em pastagem de aveia e azevém e pós-desmame à idade convencional, de acordo com a idade de desmame e o ano

\begin{tabular}{|c|c|c|c|c|c|c|c|}
\hline & \multicolumn{3}{|c|}{ Desmame precoce } & \multicolumn{3}{|c|}{ Desmame convencional } & \multirow[t]{2}{*}{$\mathrm{CV}(\%)$} \\
\hline & 2004 & 2005 & Média & 2004 & 2005 & Média & \\
\hline Peso inicial, $\mathrm{kg}$ & 168,0 & 148,5 & $158,2 \mathrm{~A}$ & 152,9 & 142,6 & $147,7 \mathrm{~B}$ & 13,3 \\
\hline Peso final, $\mathrm{kg}$ & 300,8 & 294,4 & 297,6 & 293,7 & 282,3 & 288,0 & 9,33 \\
\hline Ganho médio diário, $\mathrm{kg}^{\#}$ & $0,666 \mathrm{~b}$ & $0,760 \mathrm{a}$ & 0,713 & $0,720 \mathrm{ab}$ & $0,723 \mathrm{ab}$ & 0,722 & 11,7 \\
\hline Ganho diário pós-desmame, $\mathrm{kg}$ * & 0,696 & 0,682 & $0,689 \mathrm{~A}$ & 0,682 & 0,621 & $0,652 \mathrm{~B}$ & 11,5 \\
\hline
\end{tabular}

a,b Médias na mesma linha diferem $(\mathrm{P}<0,05)$ pelo teste $\mathrm{t}$.

A,B Médias na mesma linha diferem $(\mathrm{P}<0,05)$ pelo teste $\mathrm{F}$.

\# Ganho de peso médio diário durante o período de inverno primavera em pastagem de aveia e azevém.

* Ganho de peso médio diário do desmame à idade convencional ao final da pastagem de aveia e azevém. 
Na pastagem cultivada de aveia e azevém, houve interação significativa entre idade de desmame e ano para o ganho médio diário dos bezerros no período de maio a novembro. O ganho médio diário dos bezerros do desmame precoce em 2005 foi $14,1 \%$ superior $(\mathrm{P}<0,05)$ ao verificado em 2004. Nos animais desmamados à idade convencional, o ganho foi similar nos dois anos de observação: 0,720 e $0,723 \mathrm{~kg} /$ dia para 2004 e 2005, respectivamente. Os ganhos médios diários obtidos nesta fase são considerados razoáveis. Restle et al. (1998), em diferentes categorias animais da raça Charolesa em pastagens de aveia e azevém, determinaram ganhos de $0,847 \mathrm{~kg} / \mathrm{animal} /$ dia para bezerros com média de 10 meses de idade e $182 \mathrm{~kg}$ de peso corporal.

Os pesos ao final do período de pastejo em aveia e azevém foram de 297,6 kg e 288,0 kg para animais desmamados precocemente ou à idade convencional, respectivamente, são superiores aos obtidos por Lobato et al. (2007), de 221,3 e 233,2 $\mathrm{kg}$ para novilhos desmamados aos 70 e 180 dias, respectivamente, mantidos em pastagem de aveia, azevém e trevo-vesiculoso (Trifolium vesiculosum cv. Yuchi) em pastejos rotativos.

Não houve influência $(\mathrm{P}>0,05)$ da idade ao desmame sobre os pesos iniciais, o ganho médio diário e os pesos finais em pastagem de verão (Tabela 4). Restle et al. (1999b) também não encontraram diferença no peso ao abate aos 14 meses de idade entre animais desmamados aos 72 ou 210 dias de idade. Todavia, Pötter \& Lobato (2003) estudaram animais desmamados aos 100 ou 180 dias de idade e verificaram menores pesos $(\mathrm{P}<0,05)$ no início da terminação e ao abate dos novilhos desmamados aos 100 dias de idade. Entretanto, esses animais tiveram durante a terminação ganhos de peso de $1,399 \mathrm{~kg}$ e os do desmame à idade convencional, de $1,260 \mathrm{~kg}$. Os autores atribuíram o maior ganho de peso ao ganho compensatório pelos animais desmamados precocemente, os quais tinham sido submetidos previamente à restrição alimentar. Com pesos corporais de
328,8 e $359,4 \mathrm{~kg}$ para os desmamados aos 100 ou 180 dias, respectivamente, concluíram que o desmame precoce não constitui impedimento para o abate aos 14 meses de idade em regime de suplementação em pastagem. Almeida et al. (2003) e Lobato et al. (2007) abateram aos 24/26 meses novilhos desmamados precocemente ou à idade convencional e também não encontraram diferenças no peso corporal nem nas características de carcaças, como rendimento, conformação e espessura de gordura.

Os pesos corporais médios de 340,1 e 332,8 kg, com condições corporais médias de 4,14 e 4,15 pontos para animais do desmame precoce e convencional, respectivamente, comprovam a viabilidade do abate de novilhos aos 15-16 meses de idade quando há planejamento nutricional e sanitário adequados.

Maiores pesos de abate aos 14 meses de idade de animais desmamados aos 72 e 210 dias, 424 e $406 \mathrm{~kg}$, respectivamente, foram verificados por Restle et al. (2002a) em animais confinados do desmame aos 210 dias, cujas carcaças tiveram peso e espessura de gordura adequados ao mercado.

Os animais nascidos em 2005 e que consumiram pastagens no verão 2006/2007 obtiveram ganhos de peso inferiores aos daqueles nascidos em 2004 que pastejaram no verão 2005/2006. Os ganhos médios foram 0,523 e $0,821 \mathrm{~kg} /$ dia, respectivamente, em decorrência da qualidade das pastagens (Tabela 1). Por motivos de necessidades administrativas no estabelecimento, os animais nascidos em 2005 pastejaram Brachiaria brizantha, enquanto os nascidos em 2004 pastejaram milheto. Isso determinou o melhor desenvolvimento dos novilhos nascidos em 2004 em comparação aos nascidos em 2005.

O uso exclusivo da pastagem de braquiária no segundo ano de avaliação deve ter limitado o consumo de forragem pela alta proporção de fibra em detergente neutro no material ingerido. Amostras retiradas com cortes rentes ao solo determinaram valores de $66,85 \%$ de fibra em detergente

Tabela 4 - Desempenho de novilhos desmamados em idade precoce ou à idade convencional em pastagens de verão durante a terminação

\begin{tabular}{|c|c|c|c|c|}
\hline & \multirow[b]{2}{*}{$\mathrm{N}^{\mathrm{o}}$ animais } & \multirow[b]{2}{*}{ Peso inicial } & \multicolumn{2}{|c|}{ Período verão (pastagem cultivada) } \\
\hline & & & Peso final & Ganho médio diário \\
\hline \multicolumn{5}{|c|}{ Desmame precoce } \\
\hline 2005 & 39 & 294,4 & 332,4 & 0,497 \\
\hline Média & & 297,6 & 340,1 & 0,658 \\
\hline 2005 & 10 & 282,6 & 324,1 & 0,548 \\
\hline Média & & 288,0 & 332,8 & 0,685 \\
\hline $\mathrm{CV}(\%)$ & & 9,33 & 8,63 & 24,88 \\
\hline
\end{tabular}

$(\mathrm{P}>0,05)$ 
neutro (Tabela 1). Conforme descrito por Van Soest (1994), o teor de FDN está intimamente associado à ruminação, ao enchimento do rúmen, à taxa de passagem e ao consumo de alimento, e a FDN dos alimentos é mais relevante para a produção que sua digestibilidade. Os animais nascidos em 2004 no verão 2005/2006 (Tabela 1) receberam como alimentação pastagem de milheto com $181,25 \%$ a mais de proteína bruta e $25,53 \%$ a menos de fibra em detergente neutro se comparados àqueles em pastagem de capimbraquiária nascidos em 2005 .

O desempenho animal neste estudo em pastagem de milheto foi inferior aos encontrados por Restle et al. (2002b) em novilhos Charolês, Nelore e produtos F1 do seu cruzamento com média de 14 meses de idade submetidos a pastejo em diferentes pastagens de estação quente. Esses autores observaram em pastagem de milheto ganho médio diário de $1,188 \mathrm{~kg}$ na média dos períodos de avaliação, porém em solos corrigidos e com adubação nitrogenada de $150 \mathrm{~kg}$ de N/ha. Moojen et al. (1999), com novilhos de 13-14 meses em pastejo contínuo em milheto e avaliando diferentes níveis de nitrogênio $(0,150$ e $300 \mathrm{~kg} / \mathrm{ha})$, observaram ganhos de 0,$553 ; 0,659$; e $0,764 \mathrm{~kg}$ (PV), com aumento linear de acordo com as doses de nitrogênio.

Contudo, Moraes \& Maraschin (1988), em pesquisa com novilhos mestiços Charolês e Nelore, com pressão de pastejo de 4 e $10 \%$, observaram ganhos de pesos de 0,5 e $1,24 \mathrm{~kg}$, respectivamente. Neste trabalho verificaram-se ganhos de 0,819 e $0,822 \mathrm{~kg} /$ dia nos animais desmamados precocemente e em idade convencional, respectivamente, ganhos intermediários entre os obtidos com 4 e $10 \%$ de pressão de pastejo de Moraes \& Maraschin (1988), o que confirma a importância de uma relação adequada entre disponibilidade e qualidade de forragem, visando maior ganho de peso por animal.
As curvas de crescimento dos novilhos de acordo com o ano de nascimento e as idades de desmame, independentemente do ano de observação, apresentaram tendências semelhantes (Figura 1).

Característica importante a ser considerada no abate a idades precoces é a presença de acabamento mínimo desejado pelos mercados consumidores, determinante para o momento de abate dos novilhos.

Não houve diferenças na condição corporal entre as idades ao desmame dentro dos anos de avaliação (Figura 2). No entanto, verificou-se variação da condição corporal entre os anos de avaliação, com superioridade para os animais nascidos em 2004. Essa variação deve-se, em parte, à suplementação utilizada para esses animais $(0,5 \%$ do peso corporal com casca de soja) no período de inverno e primavera, meses de junho a outubro, a qual não refletiu em ganho de peso (Tabela 3), mas, devido ao maior aporte de energia, ocasionou deposição de gordura corporal.

A suplementação pode alterar as relações de qualidade e quantidade de consumo de forragem conforme seus efeitos aditivos ou substitutivos (Pilau \& Lobato, 2006). Neste experimento, supõe-se que ocorreu efeito aditivo no consumo de MS e melhor balanceamento da dieta, determinando nos animais nascidos em 2004 maior deposição de gordura corporal, sem diferença significativa no peso final entre os anos de observação (Tabela 4).

Na produção de novilhos destinados ao abate precoce, é fundamental o grau de acabamento dos animais, pois determina carcaças de melhor qualidade e aceitabilidade (Restle et al., 1999b; Restle et al., 2002a). Os animais nascidos em 2004 apresentaram condição corporal de 4,34 pontos aos 16 meses, superior $(\mathrm{P}<0,01)$ à daqueles nascidos em 2005 , de 3,96 pontos (Figura 2).

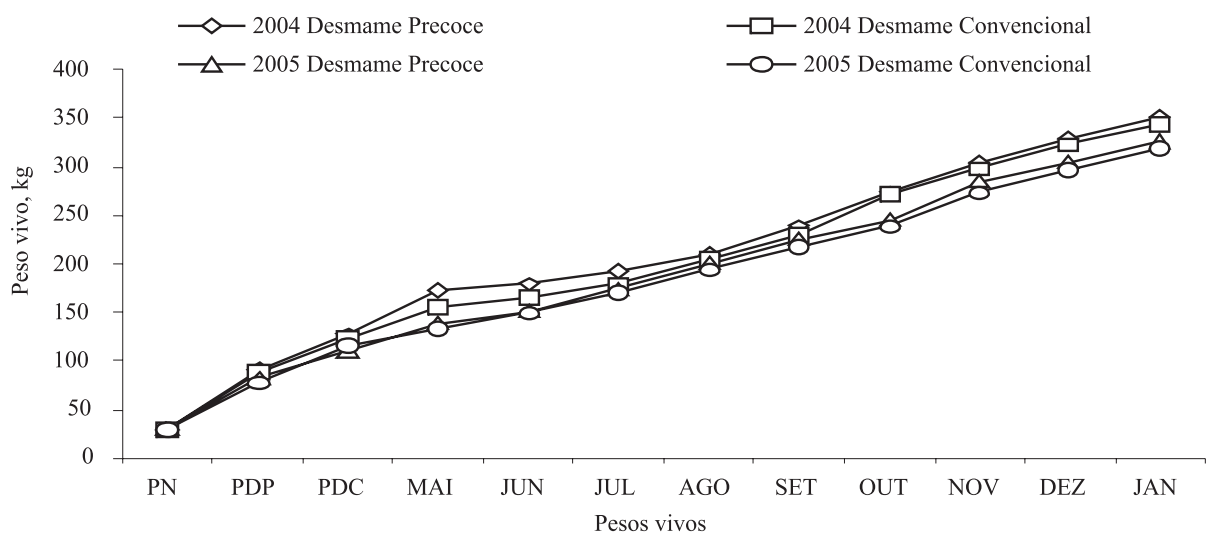

PN - Peso ao nascimento; PDP - Peso ao desmame precoce; PDC - Peso ao desmame a idade convencional

Figura 1 - Evolução do peso corporal dos novilhos do nascimento aos 15-16 meses de idade de acordo com a idade ao desmame e o ano. 


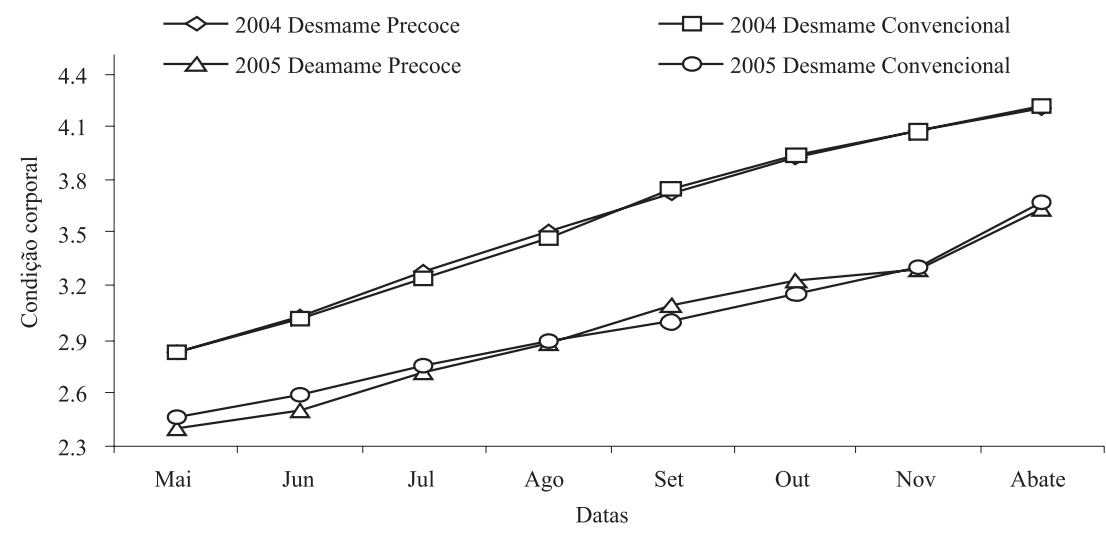

Figura 2 - Evolução da condição corporal dos novilhos, de acordo com a idade de desmame e o ano, desde $1^{\circ}$ de maio aos 15 - 16 meses de idade.

A condição corporal média de 4,34 pontos viabiliza o abate de animais jovens (13 a 16 meses de idade) com carcaças com cobertura de gordura condizente com as exigências do mercado. Entretanto, a condição corporal média de 3,69 pontos nos animais nascidos em 2005 não permitiu o abate dos animais, pois visualmente não apresentavam o grau de acabamento exigido pelos frigoríficos.

Aguinaga et al. (2006) trabalharam com novilhos mantidos em pastagem de inverno-primavera de aveia e azevém sob diferentes alturas de pastejo e abatidos aos 14 meses de idade e verificaram que o escore de condição corporal é influenciado pela altura da pastagem e que essa altura está positivamente correlacionada ao grau de acabamento das carcaças no abate dos novilhos. As condições corporais variaram entre 3,1 e 3,6 pontos e as espessuras de gordura entre 2,25 e 2,77 mm, não alcançando o mínimo necessário para serem de boa qualidade.

Valores inferiores ao deste estudo foram encontrados por Cerdótes et al. (2004a), que avaliaram o desenvolvimento de bezerros até os 12 meses de idade, filhos de vacas das raças Charolesa, Nelore e mestiças Charolesa $\times$ Nelore, desmamados em diferentes idades e verificaram condições corporais aos 12 meses de idade variando entre 2,76 e 2,79 pontos nas diferentes idades de desmame. Esses baixos valores podem ser atribuídos ao fato de os animais estarem em crescimento e a dieta não proporcionar ganhos de peso elevados, refletindo-se em baixa deposição de gordura corporal.

O valor médio de condição corporal dos dois anos de observação, de 4,15 pontos, foi superior aos relatados por Cerdótes et al. (2004a), fato que pode ser explicado pela raça utilizada, Braford, cujos animais são mais precoces que os Nelore, Charolês e seus mestiços. Entre os grupos avaliados por esses autores, os animais Nelore apresentaram menores condições corporais em todas as idades avaliadas.

\section{Conclusões}

Bezerros desmamados aos 80 dias de idade, quando alimentados adequadamente, têm desenvolvimento semelhante ao dos bezerros desmamados aos 152 dias de idade. Em sistemas de produção de ciclo completo e intensivos, é possível atingir desenvolvimento e condições de acabamento adequados para mercados específicos desde que os bezerros sejam desmamados aos 80 dias de idade e abatidos aos 15-16 meses de idade.

\section{Agradecimentos}

Ao Sr. Arizoli Gindri e seu filho João Carlos Gindri, proprietários da Fazenda Granja Itú, pelo financiamento do trabalho e pela cessão das instalações e animais para o desenvolvimento do experimento.

Ao professor José Henrique Souza da Silva, pelo auxílio nas análises estatísticas.

Ao engenheiro agrícola Paulo Rodrigo Guimarães dos Santos, pelo auxílio na coleta dos dados experimentais.

\section{Referências}

Aguinaga, A.Q.; CARVAlho, P.C.F.; ANGHinOni, I. et al. Produção de novilhos superprecoces em pastagem de Aveia e Azevém submetida a diferentes alturas de manejo. Revista Brasileira de Zootecnia, v.35, n.4, p.1756-1773, 2006.

ALBOSPINO, B.H.J.C.; LOBATO, J.F.P. Efeitos do desmame precoce de bezerros no desempenho até os 24-26 meses de idade. Revista Brasileira de Zootecnia, v.23, n.4, p.565-575, 1994.

ALMEIDA, L.S.P.; LOBATO, J.F.P. Data de desmame e desempenho reprodutivo de vacas de corte. Revista Brasileira de Zootecnia, v.31, n.3, p.1223-1229, 2002.

ALMEIDA, L.S.P.; LOBATO, J.F.P.; SCHENKEL, F.S. Idade de desmame e suplementação no desenvolvimento e em características de carcaças de novilhos de corte. Revista Brasileira de Zootecnia, v.32, n.6, p.1713-1721, 2003 (supl.1). 
ASSOCIATION OF OFFICIAL ANALYTICAL CHEMITS - AOAC. Official methods of analysis. 14 ed. Washington, D.C., 1984. $1141 \mathrm{p}$.

BAIL, C.A.T.; BRONDANI. I.L.; RESTle, J. Níveis de concentrado na fase de terminação em confinamento para novilhos previamente mantidos em pastagem nativa ou cultivada. Ciência Rural, v.30, n.1, p.151-157, 2000.

BeretTA, V.; LOBATO, J.F.P.; MIELITZ NETO, C.G.A. Produtividade e eficiência biológica de sistemas pecuários de cria diferindo na idade das novilhas ao primeiro parto e na taxa de natalidade do rebanho no Rio Grande de Sul. Revista Brasileira de Zootecnia, v.30, n.4, p.1278-1286, 2001

BERETTA, V.; LOBATO, J.F.P.; MIELITZ NETO, C.G.A. Produtividade e eficiência biológica de sistemas de recria e engorda de gado de corte no Rio Grande de Sul. Revista Brasileira de Zootecnia, v.31, n.2, p.696-706, 2002a.

BeretTA, V.; LOBATO, J.F.P.; MIELitz NETO, C.G.A. Produtividade e eficiência biológica de sistemas de produção de gado de corte de ciclo completo no Rio Grande do Sul. Revista Brasileira de Zootecnia, v.31, n.2, p.991-1001, 2002b (supl.).

CERDÓTES, L.; RESTLE, J.; ALVES FILHO, D.C. et al. Desenvolvimento de bezerros de corte filhos de vacas submetidas a diferentes manejos alimentares, desmamados aos 42 ou 63 dias de idade. Revista Brasileira de Zootecnia, v.33, n.3, p.597-609, 2004a.

CERDÓTES, L.; RESTLE, J.; ALVES FILHO, D.C. et al. Produção e composição do leite de vacas de quatro grupos genéticos submetidas a dois manejos alimentares no período de lactação. Revista Brasileira de Zootecnia, v.33, n.3, p.610-622, 2004b.

DI MARCO, O.N. Crescimento de vacunos para carne. Mar Del Plata: Balcarce, 1998. 247p.

EMPRESA BRASILEIRA DE PESQUISA AGROPECUÁRIA EMBRAPA. Sistema brasileiro de classificação de solos. Brasília: Embrapa Cerrados: Rio de Janeiro: Centro Nacional de Pesquisa de Solos, 1999. 412p.

FREETLY, H.C. The replacement heifer and the primiparous cow. In: REUNIÃO ANNUAL DA SOCIEDADE BRASILEIRA DE ZOOTECNIA, 36., 1999, Porto Alegre. Anais... Porto Alegre: SBZ, 1999. p.241-249.

FREITAS, E.A.; LOPEZ, J.; PRATES, E.R. Produtividade de matéria seca, proteína digestível, e nutrientes digestíveis totais em pastagem nativa do Rio Grande do Sul. Anuário Técnico IPZFO, v.3, p.454-515, 1976.

HAYDOCK, K.P.; SHAW, N.H. The comparative yield method for stimating dry matter yield of pasture. Australian Journal of Experimental Agriculture and Animal Husbandry, v.15, n.76, p.663-670, 1975

LOBATO, J.F.P.; MÜLleR, A.; PEREIRA NETO, O.A. et al. Efeitos da idade à desmama sobre o desempenho reprodutivo de vacas de corte primíparas. Revista Brasileira de Zootecnia, v.29, n.6, p.2013-2018, 2000 (supl.1).

LOBATO, J.F.P.; ALMEIDA, L.S.P.; OSÓRIO, E.B. et al. Efeito da idade de desmame no desenvolvimento e nas características de carcaça de novilhos de corte. Revista Brasileira de Zootecnia, v.36, n.3, p.596-602, 2007.

LOWMAN, B.G.; SCOTT, N.; SOMERVILle, S. Condition scoring beef cattle. Edinburgh: East of Scotland College of Agriculture. 1973. 8p.

MOOJEN, E.L.; LUPATINI, G.C.; RESTLE, J. et al. Produção animal em pastagem de milheto sob diferentes níveis de nitrogênio. Pesquisa Agropecuária Brasileira, v.34, n.11, p.2145-2149, 1999.

MORAES, A.; MARASCHIN, G.E. Pressões de pastejo e produção animal em milheto cv. comum. Pesquisa Agropecuária Brasileira, v.23, n.2, p.197-205, 1988.

MORENO, J.A. Clima do Rio Grande do Sul. Porto Alegre: Secretaria da Agricultura, 1961. 41p.

NATIONAL RESEARCH COUNCIL - NRC Nutrient requeriment of beef cattle. Washington D.C.: National Academy Press, 1996. $244 \mathrm{p}$.
PILAU, A.; LOBATO, J.F.P. Recria de bezerras com suplementação no outono e pastagem cultivada de inverno. Revista Brasileira de Zootecnia, v.35, n.6, p.2388-2396, 2006.

POPPI, D.P.; McLENANN, S.R. Protein and energy utilization by ruminants at pasture. Journal of Animal Science, v.73, n.1, p.278-290, 1995 .

PÖTTER, B.A.A.; LOBATO, J.F.P. Desempenho e características quantitativas de carcaça de novilhos Braford desmamados aos 100 ou 180 dias de idade e abatidos aos 13-14 meses. Revista Brasileira de Zootecnia, v.32, n.5, p.1220-1226, 2003.

PÖTTER, B.A.A.; LOBATO, J.F.P.; SCHENKEL, F.S. Efeitos do manejo pós-parto de vacas primíparas no desempenho de bezerros de corte até um ano de idade. Revista Brasileira de Zootecnia, v.33, n.2, p.426-433, 2004.

PÖTTER, L.; LOBATO, J.F.P.; MIELITZ NETO, C.G.A. Produtividade de um modelo de produção para novilhas de corte primíparas aos dois, três e quatro anos de idade. Revista Brasileira de Zootecnia, v.27, n.3, p.613-619, 1998.

QUADROS, S.A.F.; LOBATO, J.F.P. Efeitos da lotação animal na produção de leite de vacas de corte primíparas e no desenvolvimento dos seus bezerros. Revista Brasileira de Zootecnia, v.26, n.1, p.27-33, 1997.

RESTle, J.; LUPATINI, G.C.; ROSO, C. et al. Eficiência e desempenho de categorias de bovinos de corte em pastagem cultivada. Revista Brasileira de Zootecnia, v.27, n.2, p.397-404, 1998

RESTle, J.; POLli, V.A.; Alves FILho, D.C. et al. Desenvolvimento de bovinos de corte de diferentes grupos genéticos desmamados aos 3 ou 7 meses de idade. Revista Brasileira de Zootecnia, v.28, n.5, p.1023-1030, 1999a.

RESTLE, J.; VAZ, F.N.; BRONDANI, I.L. et al. Estudo da carcaça de machos Braford desmamados aos 72 ou 210 dias, abatidos aos 14 meses. Pesquisa Agropecuária Brasileira, v. 34, n.11, p.2137-2144, 1999b.

RESTlE, J.; VAZ, R.Z.; ALVES FILHO, D.C. et al. Desempenho de vacas Charolês e Nelore desterneiradas aos três ou sete meses. Revista Brasileira de Zootecnia, v.30, n.2, p.499-507, 2001.

RESTLE, J.; ROSO, C.; AITA, V. et al. Produção animal em pastagem com gramíneas de estação quente. Revista Brasileira de Zootecnia, v.31, n.3, p.1491-1500, 2002b.

RESTLE, J.; NEUMANN, M.; BRONDANI, I.L. et al. Produção do superprecoce a partir de bezerros desmamados aos 72 ou 210 dias de idade. Revista Brasileira de Zootecnia, v.31, n.4, p.1803-1813, 2002a

RIBEIRO, E.L.A.; RESTLE, J. Desempenho de terneiros Charolês e Abeerden Angus puros e seus mestiços com Nelore. Pesquisa Agropecuária Brasileira, v.26, n.8, p.1145-1151, 1991.

ROSADO JÚNIOR, A.G.; LOBATO, J.F.P. Application of a model of management by macroprocesses to a beef cattle enterprise: a case study. Revista Brasileira de Zootecnia, v.38, n.11, p.2280-2288, 2009 .

SIMEONE, A.; LOBATO, J.F.P. Efeitos da carga animal em campo nativo e do controle da amamentação no desenvolvimento de bezerros mestiços até um ano de idade. Revista Brasileira de Zootecnia, v.27, n.1, p.179-185, 1998.

STATISTICAL ANALYSIS SYSTEM - SAS. SAS/STAT user's guide: statistics. 4.ed. Version 6. Cary: 1997. v.2, 943p.

VAN SOEST, P.J. Nutritional ecology of the ruminant. 2.ed. Ithaca: Cornell University Press, 1994. 476p.

VAZ, R.Z.; LOBATO, J.F.P. Effects of the weaning age of calves on somatic development and on reproductive performance of beef cows. Revista Brasileira de Zootecnia, v.39, n.5, p.1058-1067, 2010.

VIEIRA, A.; LOBATO, J.F.P.; TORRES JÚNIOR, R.A. et al. Fatores determinantes do desempenho reprodutivo de vacas Nelore na Região dos Cerrados do Brasil central. Revista Brasileira de Zootecnia, v.34, n.6, p.2408-2416, 2005 (supl.). 